\title{
Association between underweight and hospitalization, emergency room visits, and mortality among patients in community medical homes
}

This article was published in the following Dove Press journal:

Risk Management and Healthcare Policy

17 January 2013

Number of times this article has been viewed

\author{
Paul Y Takahashi' \\ Jennifer L St Sauver ${ }^{2}$ \\ Timothy C Olson' \\ Jill M Huber' \\ Stephen S Cha ${ }^{2}$ \\ Jon O Ebbert ${ }^{\prime}$ \\ 'Division of Primary Care Internal \\ Medicine, ${ }^{2}$ Department of Health \\ Sciences Research, Mayo Clinic, \\ Rochester, MN, USA
}

Correspondence: Paul Y Takahashi Mayo Clinic, 200 First Street SW,

Rochester, MN 55905, USA

Tel + I 50728425 | I

Fax +I 5072660036

Email takahashi.paul@mayo.edu
Background: In older adults, underweight (body mass index $[\mathrm{BMI}]<18.5$ ) has been associated with increased mortality. This increased mortality risk may be associated with increased health care utilization. We evaluated the relationship between underweight and hospitalization, emergency room visits, and mortality.

Methods: An analysis of a retrospective cohort study was conducted at a multisite academic primary care medical practice in Minnesota. The patients were $\geq 60$ years of age, impaneled within primary care on January 1, 2011, and had a BMI measurement recorded between January 1, 2011, and December 31, 2011. Individuals were excluded if they refused review of their medical record. The primary measurement was BMI, which was categorized as underweight (BMI $<18.5$ ) or normal and obese (BMI $\geq 18.5$ ). The outcomes were hospitalization, emergency room visits, and mortality in the 2011 calendar year. Associations between underweight and each outcome were calculated using logistic regression. Interactions between underweight and gender were assessed in the logistic regression models. The final results were adjusted for age, gender, comorbid health conditions, and single living status.

Results: The final cohort included 21,019 patients, of whom 220 (1\%) were underweight. Underweight patients had a higher likelihood of hospitalization compared with patients with higher BMI (adjusted odds ratio [OR] 1.64; 95\% confidence interval [CI] 1.21-2.22). Underweight patients were also more likely to visit the emergency room (adjusted OR 1.70; 95\% CI 1.28-2.25) or to die (adjusted OR 3.64; 95\% CI 2.33-5.69). Men with a BMI $<18.5$ compared with those having a BMI $\geq 18.5$ had the highest odds of hospitalization (OR 3.45; 95\% CI 1.59-7.48).

Conclusion: Underweight older adults, especially men, have higher odds of hospitalization, emergency room visits, and mortality. Future work on underweight might involve improving weight status, which may reduce the risk of hospitalization, emergency room visits, and mortality.

Keywords: aging, health care utilization, nutrition, population health

\section{Introduction}

A low body mass index (BMI) is often associated with low nutritional status and adverse health outcomes. ${ }^{1}$ Among older patients, low BMI may place the patient at risk for sarcopenia and functional debility. ${ }^{2}$ Low nutritional status adversely affects mobility. ${ }^{3}$ Functional debility could potentially lead to hospitalization and emergency room visits related to falls and fractures, and increased susceptibility to illness. 
Within large populations, a "J curve" relationship has been observed for individuals with the highest and lowest BMIs who are at the greatest risk for mortality. ${ }^{4}$ Adults over 80 years of age with a BMI $<22$ have increased mortality compared with adults having higher BMI. ${ }^{5}$

Within the medical home model, organizations are attempting to identify risk factors for hospitalization and emergency room visits to control costs and preserve functionality. Most risk stratification models stress comorbid illness, like Medicare's hierarchical condition codes. ${ }^{6}$ Investigators have attempted to look at other factors, eg, psychosocial factors, to help predict high health care utilization. ${ }^{7}$ We sought to determine the relationship between underweight (BMI $<18.5)$, hospitalization, and emergency room visits in an older population to refine our risk stratification further within the medical home model.

In order to investigate the relationship between BMI, hospitalization, and emergency room visits, we undertook a retrospective cohort study of all patients enrolled in a primary care medical home at Mayo Clinic in Rochester and Kasson, MN. We hypothesized that patients who were underweight would be more likely to be hospitalized, have at least one emergency room visit, and be more likely to die during the study period than patients with higher BMI.

\section{Materials and methods Study design}

We conducted this retrospective cohort study using administrative data from the electronic medical record. The study was approved by the Mayo Clinic institutional review board in May 2012.

\section{Setting}

The study was conducted at an academic primary care medical practice with multiple practice locations in rural Kasson, MN, two suburban Rochester clinics positioned at Northeast and Northwest Rochester, and a downtown urban Rochester practice. All patients received their primary care through Employee and Community Health at the Mayo Clinic, where care is provided by family practitioners and general internists. The two hospitals within the Mayo Clinic system in Rochester are Saint Marys Hospital and Rochester Methodist Hospital. Saint Marys is a 1265-bed hospital with 55 operating rooms, and Rochester Methodist Hospital has 791 patient rooms and 41 operating rooms.

\section{Patient population}

Patients were included if they were impaneled in Employee and Community Health on January 1, 2011, and were $\geq 60$ years of age. Patients were excluded if they did not have a BMI calculated during the 3 years prior to January 1 , 2011 , or if they refused medical record review in accordance with Minnesota State Law. ${ }^{8}$

\section{Variables}

The primary independent variable was BMI, calculated as weight in kilograms divided by height in meters squared. The BMI was obtained from the electronic medical record as listed on the date closest to January 1, 2011, within three years. The BMI was categorized based upon Centers for Disease Control and World Health Organization criteria. ${ }^{9}$ We categorized patients with a BMI $<18.5$ as underweight and the remaining BMIs as follows: 18.5-24.9, normal weight; 25-29.9, overweight; 30-34.9, obese class I; 35-35.9, obese class II; and $\geq 40.0$ obese class III. $^{9}$

Other variables included age, gender, white versus nonwhite race, home-living status, use of an interpreter during medical interviews, and Charlson comorbidity score. Age, gender, race, interpreter, and living status were obtained from the electronic medical record. Nonwhite races (black, Indian, white [Hispanic], Asian, and others) were combined because the number of nonwhites in this population was low. Living status was defined as living alone (single or widowed), married, or other committed status. The Charlson comorbidity score is a composite index of comorbid health conditions, including myocardial infarction, heart failure, peripheral vascular disease, stroke, dementia, pulmonary disease, ulcer, liver disease, diabetes, diabetes with organ damage, hemiplegia, renal disease, severe liver disease, metastatic solid tumors, acquired immunodeficiency syndrome, cancer, and rheumatological disorders. ${ }^{10}$ All the factors were weighted 1 point with the exception of acquired immunodeficiency syndrome and metastatic solid tumors, which are weighted 6 points; cancer, severe renal disease, diabetes with end-organ damage, and hemiplegia weighted 2 points; and severe liver disease weighted 3 points. Charlson comorbidity scores were calculated using ICD-9 codes obtained from billing records. The Charlson index has been observed to predict rates of hospitalization and mortality. ${ }^{10,11}$

The outcomes of interest were hospitalization, emergency room visits, and mortality within the study year. Hospitalization was defined as inpatient hospitalization on an urgent or elective basis. Colonoscopy and outpatient procedures performed in the hospital were excluded. Hospitalization and emergency room visits were obtained using Mayo Clinic billing records. Mortality was obtained from the electronic medical record for all patients. Mortality information was 
updated based on death within facilities in Olmsted County and local reporting sources like newspapers.

\section{Statistical methods}

The initial cohort was characterized overall and by all BMI classifications. Analysis of variance was used to compare distribution of continuous variables of age, BMI, and Charlson score. Pearson Chi-square tests were used to compare the proportion of dichotomous variables across all BMI categories. Normal, overweight, and obese patients were combined into a single comparison group for all remaining analyses. Univariate associations between low BMI and hospitalization, emergency room visits, and mortality were calculated using logistic regression to estimate odds ratios $(\mathrm{OR})$ and associated 95\% confidence intervals (CI). Multivariate logistic regression models included variables that differed across BMI categories. We also performed subgroup analyses by gender and BMI category, with women of BMI $>18.5$ serving as the referent category. Significance of interaction terms was assessed by logistic regression. The $95 \% \mathrm{CI}$ was calculated to evaluate the statistical significance of the findings. The initial characteristics of the cohort based on BMI were compared, with $P<0.05$ being significant.

\section{Results}

\section{Patients}

The potentially eligible cohort consisted of 22,913 individuals $\geq 60$ years of age enrolled in Employee and Community Health on January 1, 2011. Of these patients, 21,019 $(92 \%)$ had a BMI calculated within 3 years and met the entry criteria. Overall, 220 patients (1\%) were underweight (Table 1). The average time from BMI to January 1, 2011 was $185 \pm 212$ days. Only $4 \%$ of patients had BMI over 2 years old. The outcomes of hospitalization, emergency room visits, and mortality differed little between those of normal weight and those in the four categories of exceeding normal weight. For further analysis, we combined the normal weight and obesity categories into a single category of BMI $\geq 18.5$.

\section{Hospitalization, emergency room visits, and mortality}

Underweight patients (BMI < 18.5) were more likely to be hospitalized during 2011 compared with those having a BMI $\geq 18.5$. In the entire cohort, there were 3480 hospitalizations (17\%) within the study year. In the underweight cohort, there were 68 hospitalizations (31\%) compared with 3412 hospitalizations (16\%) in the normal weight cohort. The OR for hospitalization in underweight versus normal/obese patients was 2.28 (95\% CI 1.71-3.04) unadjusted and 1.68 (95\% CI 1.25-2.27) age-adjusted (Table 2). Further adjustment for single status and comorbid illnesses did not markedly change the OR.

Underweight patients were more likely to visit the emergency room or die compared with normal and obese patients. For emergency room visits, $40.9 \%$ (90/220) of the underweight patients had an emergency room visit in 2011 compared with $23.0 \%(4808 / 20,889)$ of the patients with $\mathrm{BMI} \geq 18.5$. Underweight patients were nearly twice as likely to have had at least one emergency room visit compared with patients with a BMI $\geq 18.5$ (age-adjusted OR 1.76; 95\% CI 1.34-2.33, Table 2). A higher percentage of underweight patients died $(12.7 \% ; 28 / 220)$ compared with patients with $\mathrm{BMI} \geq 18.5(2.5 \% ; 516 / 20,889)$. Underweight patients were over three times more likely to die in 2011 compared with patients with BMI $\geq 18.5$ (fully adjusted OR 3.64; 95\% CI 2.33-5.69).

\section{Gender stratification}

Underweight status was a risk factor for hospitalization, emergency room visits, and mortality in both men and women. We observed that underweight men were nearly 3.5 times more likely to be hospitalized compared with women with BMI $\geq 18.5$ (interaction term, $P=0.04$, Table 3 ). Similar results were observed for emergency room visits; however, the interaction was not statistically significant (interaction term, $P=0.10$ ).

\section{Discussion}

In this retrospective cohort study of 21,019 subjects $\geq 60$ years of age within a primary care medical home, we observed that underweight subjects (BMI $<18.5$ ) were 1.6 times more likely to be hospitalized within a year compared with patients with $\mathrm{BMI} \geq 18.5$. We also found that patients with low BMI had increased odds of emergency room visits and mortality. Men with low BMI appeared to be at the highest risk for these outcomes. One percent of our population was underweight, which is slightly lower than in the NHANES III population in the 1990s. ${ }^{12}$ Our findings emphasize the importance of underweight status in older adults living in the community. While underweight status has a low prevalence, patients who are underweight are a high-risk group for hospitalization, and low BMI may potentially be amenable to intervention.

Our study adds to the findings of other studies observing adverse outcomes in underweight patients. In a prospective longitudinal study of 722 patients $\geq 80$ years of age, the investigators observed an increased mortality rate with 
Table I Characteristics of 21,019 patients $\geq 60$ years by BMI classification

\begin{tabular}{|c|c|c|c|c|c|c|c|c|}
\hline $\begin{array}{l}\text { Patient } \\
\text { characteristics }\end{array}$ & $\begin{array}{l}\text { Overall } \\
n=21019\end{array}$ & $\begin{array}{l}<18.5 \\
n=220\end{array}$ & $\begin{array}{l}18.5-24.9 \\
n=4909\end{array}$ & $\begin{array}{l}25.0-29.9 \\
n=7874\end{array}$ & $\begin{array}{l}30.0-34.9 \\
n=4948\end{array}$ & $\begin{array}{l}35.0-35.9 \\
n=1988\end{array}$ & $\begin{array}{l}\geq 40.0 \\
n=1080\end{array}$ & $P$-value \\
\hline Age (mean, SD) & $72.03,8.88$ & $78.1,9.59$ & $73.8,9.73$ & $72.5,8.80$ & 7I, 8.26 & $69.6,7.56$ & $68.4,7.08$ & $<0.00 I^{\mathrm{a}}$ \\
\hline Sex, female, n (\%) & II 664 (55) & $192(87)$ & 3401 (69) & $3904(50)$ & $2374(48)$ & $|I 2|(56)$ & $672(62)$ & $<0.00 \mathrm{I}^{\mathrm{b}}$ \\
\hline Race, white, n (\%) & $19826(94)$ & $209(95)$ & 4545 (93) & $7438(94)$ & 4707 (95) & $1889(95)$ & $1038(96)$ & $<0.00 \mathrm{I}^{\mathrm{b}}$ \\
\hline $\begin{array}{l}\text { Marital status, } \\
\text { single, } \mathrm{n}(\%)\end{array}$ & $6240(30)$ & III (50) & I69| (34) & 2161 (27) & 1350 (27) & $593(30)$ & $334(31)$ & $<0.00 \mathrm{I}^{\mathrm{b}}$ \\
\hline $\begin{array}{l}\text { Charlson score } \\
\text { (mean, SD) }\end{array}$ & $2.05,2.57$ & $2.7 \mathrm{I}, 2.96$ & $1.95,2.6 \mathrm{I}$ & $1.94,2.5 \mid$ & $2.09,2.54$ & $2.3 \mathrm{I}, 2.6 \mathrm{I}$ & $2.55,2.63$ & $<0.00 I^{\mathrm{a}}$ \\
\hline \multicolumn{9}{|l|}{ Outcomes } \\
\hline $\begin{array}{l}\text { Hospitalization, } \\
\text { n (\%) }\end{array}$ & 3480 (17) & $68(31)$ & $87 \mid(18)$ & $1165(15)$ & $793(16)$ & 375 (19) & $208(19)$ & $<0.00 \mathrm{I}^{\mathrm{b}}$ \\
\hline ER visit, n (\%) & $4898(23)$ & $90(4 I)$ & $1209(25)$ & $1692(21)$ & II 22 (23) & $507(26)$ & $278(26)$ & $<0.00 \mathrm{I}^{\mathrm{b}}$ \\
\hline Mortality, n (\%) & $544(3)$ & $28(13)$ & $200(4)$ & |7| (2) & I0I (2) & $29(I)$ & $15(1)$ & $<0.00 I^{b}$ \\
\hline
\end{tabular}

Notes: ${ }^{\mathrm{T} T e s t}$ for comparison: ANOVA; ${ }^{\mathrm{b}}$ Pearson Chi square test.

Abbreviations: BMI, body mass index; ER, emergency room; SD, standard deviation.

underweight older adults $(\mathrm{BMI}<22.0){ }^{5}$ In 793 surgical patients, investigators found higher surgical mortality in underweight adults (BMI < 18.5) compared with normal weight patients. ${ }^{13}$ In a cohort study of older adults using the Medicare dataset, there was an increased relative risk of hospitalization of 1.22 (95\% CI 1.1-1.4) among the lowest BMI quintile compared with the middle quintile. ${ }^{14}$ However, in a Canadian cohort of 28,767 patients, no differences were observed in the costs of hospitalization between underweight individuals with BMI $<18.5$ and those of normal weight in the overall cohort of patients $\geq 18$ years of age nor in a subgroup aged $\geq 60$ years. ${ }^{15}$ In that study, most of the patients in the underweight category were 18-39 years of age.

The relationship between underweight and mortality has also been observed in previous studies. In one longitudinal study, 983 underweight individuals (BMI $<18.5$ ) with an average age of 75.3 years had higher three-year mortality rates compared with those having higher BMI. ${ }^{16}$ The association between underweight BMI and mortality has been observed in different ethnic populations, including Hispanics. ${ }^{17}$ Additionally, underweight patients with congestive heart failure have higher mortality rates compared with individuals having higher BMI. ${ }^{18}$ Relatively few data are available on the relationship between underweight and risk of emergency room visits. Malnutrition was associated with emergency room visits in 198 older patients over 75 years of age. ${ }^{19}$ However, malnutrition does differ from low BMI; thus, the evidence between underweight and emergency room visits is less well defined than with mortality or hospitalization.

We observed that underweight was associated with hospitalization. We had previously observed that age and previous hospital days were the largest risk factors for hospitalization within a similar cohort which formed the basis for the Elder risk assessment index. ${ }^{20}$ Most risk stratification models use comorbid conditions, including the Pra, ${ }^{21}$ ambulatory care group, ${ }^{22}$ and Elder risk assessment. ${ }^{20}$ Interestingly, no commonly used risk stratification model uses underweight status as a predictor of risk for hospitalization.

Our study has several limitations. First, we may have missed hospitalizations, emergency room visits, and mortality within the population. People may travel to other centers for medical care or may die out of hospital. Missing outcome data would likely decrease our outcome rates, but would not likely have differed between BMI groups. Second, the BMI measurements are based upon measurements within 3 years of January 1, 2011. On average, most individuals have fairly stable weights until the age of 60 years and then experience

Table 2 Associations between low BMI $(<18.5)$ and adverse outcomes in $201 \mathrm{I}$

\begin{tabular}{|c|c|c|c|c|c|c|}
\hline \multirow[t]{2}{*}{ Outcome } & \multicolumn{2}{|c|}{ Unadjusted } & \multicolumn{2}{|c|}{ Age-adjusted } & \multicolumn{2}{|c|}{$\begin{array}{l}\text { Age-sex-single-status- } \\
\text { Charlson score adjusted }\end{array}$} \\
\hline & OR & $95 \% \mathrm{Cl}$ & OR & $95 \% \mathrm{Cl}$ & OR & $95 \% \mathrm{Cl}$ \\
\hline Hospitalization & 2.28 & I.7I, 3.04 & 1.68 & $1.25,2.27$ & 1.64 & $1.21,2.22$ \\
\hline ER visit & 2.30 & I.76, 3.02 & 1.76 & I. $34,2.33$ & 1.70 & $1.28,2.25$ \\
\hline Mortality & 5.73 & $3.82,8.61$ & 3.26 & $2.13,5.01$ & 3.64 & $2.33,5.69$ \\
\hline
\end{tabular}

Abbreviations: $\mathrm{BMI}$, body mass index; $\mathrm{Cl}$, confidence interval; $\mathrm{ER}$, emergency room; OR, odds ratio. 
Table 3 ORs and $95 \%$ Cls assessing the interactions between sex and BMI

\begin{tabular}{|c|c|c|c|c|c|c|c|}
\hline \multirow[t]{2}{*}{ Category } & \multirow[t]{2}{*}{$\mathbf{n}$} & \multicolumn{2}{|c|}{ ER visit in $20 \mathrm{I} \mathrm{I}^{\mathrm{a}}$} & \multicolumn{2}{|c|}{ Hospitalization in $20 \mathrm{I}^{\mathrm{b}}$} & \multicolumn{2}{|c|}{ Death in $20 \mathrm{II}^{\mathrm{c}}$} \\
\hline & & $\mathbf{O R}^{\mathrm{d}}$ & $95 \% \mathrm{Cl}$ & $\mathbf{O R}^{\mathrm{d}}$ & $95 \% \mathrm{Cl}$ & $\mathbf{O R}^{\mathrm{d}}$ & $95 \% \mathrm{Cl}$ \\
\hline Women, BMI $\geq 18.5$ & 11472 & Referent & - & Referent & - & Referent & - \\
\hline Men, $\mathrm{BMI} \geq 18.5$ & 9327 & 0.99 & $0.92-1.06$ & 1.00 & $0.92-1.08$ & 0.97 & $0.97-0.97$ \\
\hline Women, BMI < 18.5 & 192 & 1.54 & $1.14-2.10$ & 1.42 & $1.03-2.01$ & 3.36 & $3.32-3.39$ \\
\hline Men, $\mathrm{BMI}<18.5$ & 28 & 3.06 & $1.4 I-6.64$ & 3.45 & I.59-7.48 & 16.80 & $6.65-42.41$ \\
\hline
\end{tabular}

Notes: anteraction term $P$-value $=0.10$; interaction term $P$-value $=0.04$; cinteraction term $P$-value $=<0.0 \mathrm{I}$; ${ }^{\mathrm{O}} \mathrm{ORs}$ adjusted for age, single status, and Charlson score. Abbreviations: $\mathrm{BMI}$, body mass index; $\mathrm{Cl}$, confidence interval; $\mathrm{ER}$, emergency room; OR, odds ratio.

a gradual weight loss. ${ }^{23}$ Thus, the previously recorded BMI should closely reflect the BMI on January 1, 2011. If the $8 \%$ of patients without a BMI measured were healthier and required less care, this could have possibly reduced the potential impact of our findings. Third, adjustments for comorbid conditions and use of ICD-9 codes can be a source of bias through misdiagnosis or miscoding a disease or condition. However, this type of error should be similar amongst BMI groups. Lastly, there may be other factors that could serve as confounders that we did not take into account when adjusting in the final model. One important factor is previous weight loss which, as a component of the frailty phenotype, may predict adverse health outcomes. ${ }^{24}$ There is a potential for higher weight loss in the underweight group compared with others. Psychosocial factors like caregiver support are often difficult to capture fully in the medical environment, and may play a role in both weight and hospitalizations. This study was conducted in a location with a predominantly white population (95\%), so the ability to generalize to other races and ethnic groups may be limited.

Our observations suggest that underweight status is a risk for adverse health outcomes and should be recognized as a risk factor by clinical providers. Future work should evaluate the utility of adding underweight to existing risk stratification methods, like the ambulatory care group or elder risk assessment instruments. Underweight patients may be appropriate candidates for case management within the medical home model. The potential benefit of enrolling underweight patients into a medical home model and providing nutritional support is unclear, and offers a potential area of growth for both practice and research.

\section{Acknowledgments}

We acknowledge the Department of Medicine Clinical Research Office for supporting this research. The authors would also like to thank Gladdie Hebl from Mayo Clinic Grant and Publication Support Services for providing editorial assistance.

\section{Disclosure}

PYT serves on the board of the American Medical Directors Association. The other authors report no conflicts of interest in this work.

\section{References}

1. Ringback Weitoft G, Eliasson M, Rosen M. Underweight, overweight and obesity as risk factors for mortality and hospitalization. Scand $J$ Public Health. 2008;36(2):169-176.

2. Inzitari M, Doets E, Bartali B, et al. Nutrition in the age-related disablement process. J Nutr Health Aging. 2011;15(8):599-604.

3. Vivanti A, Ward N, Haines T. Nutritional status and associations with falls, balance, mobility and functionality during hospital admission. J Nutr Health Aging. 2011;15(5):388-391.

4. Engeland A, Bjorge T, Selmer RM, Tverdal A. Height and body mass index in relation to total mortality. Epidemiology. 2003;14(3): 293-299.

5. Rajala SA, Kanto AJ, Haavisto MV, Kaarela RH, Koivunen MJ, Heikinheimo RJ. Body weight and the three-year prognosis in very old people. Int J Obes. 1990;14(12):997-1003.

6. Mosley DG, Peterson E, Martin DC. Do hierarchical condition category model scores predict hospitalization risk in newly enrolled Medicare advantage participants as well as probability of repeated admission scores? J Am Geriatr Soc. 2009;57(12):2306-2310.

7. Preyde M, Brassard K. Evidence-based risk factors for adverse health outcomes in older patients after discharge home and assessment tools: a systematic review. J Evid Based Soc Work. 2011;8(5):445-468.

8. Minnesota Department of Education. Minnesota Health Information Privacy Matrix, 2003. Available from: http://www.health.state.mn.us/e-health/ mpsp/legwg/legstpreana1062706.pdf. Accessed December 13, 2012.

9. World Health Organization. BMI Database and Classification, 2012. Available from: http://apps.who.int/bmi/index.jsp?introPage=intro_3 html. Accessed September 20, 2012.

10. Charlson ME, Pompei P, Ales KL, MacKenzie CR. A new method of classifying prognostic comorbidity in longitudinal studies: development and validation. J Chronic Dis. 1987;40(5):373-383.

11. Chaudhry S, Jin L, Meltzer D. Use of a self-report-generated Charlson Comorbidity Index for predicting mortality. Med Care. 2005;43(6): 607-615.

12. Kuczmarski RJ, Carroll MD, Flegal KM, Troiano RP. Varying body mass index cutoff points to describe overweight prevalence among US adults: NHANES III (1988 to 1994). Obes Res. 1997;5(6):542-548.

13. Gupta R, Knobel D, Gunabushanam V, et al. The effect of low body mass index on outcome in critically ill surgical patients. Nutr Clin Pract. 2011;26(5):593-597.

14. Luchsinger JA, Lee WN, Carrasquillo O, Rabinowitz D, Shea S. Body mass index and hospitalization in the elderly. J Am Geriatr Soc. 2003; 51(11):1615-1620.

15. Tarride JE, Haq M, Taylor VH, et al. Health status, hospitalizations, day procedures, and physician costs associated with body mass index (BMI) levels in Ontario, Canada. Clinicoecon Outcomes Res. 2012;4: 21-30. 
16. Locher JL, Roth DL, Ritchie CS, et al. Body mass index, weight loss, and mortality in community-dwelling older adults. J Gerontol A Biol Sci Med Sci. 2007;62(12):1389-1392.

17. Fontaine KR, McCubrey R, Mehta T, et al. Body mass index and mortality rate among Hispanic adults: a pooled analysis of multiple epidemiologic data sets. Int J Obes. 2012;36(8):1121-1126.

18. Curtis JP, Selter JG, Wang Y, et al. The obesity paradox: body mass index and outcomes in patients with heart failure. Arch Intern Med. 2005;165(1):55-61.

19. Yang Y, Brown CJ, Burgio KL, et al. Undernutrition at baseline and health services utilization and mortality over a 1-year period in older adults receiving Medicare home health services. J Am Med Dir Assoc. 2011;12(4):287-294.

20. Crane SJ, Tung EE, Hanson GJ, Cha S, Chaudhry R, Takahashi PY. Use of an electronic administrative database to identify older community dwelling adults at high-risk for hospitalization or emergency department visits: the elders risk assessment index. BMC Health Serv Res. 2010;10:338.
21. Pacala JT, Boult C, Reed RL, Aliberti E. Predictive validity of the Pra instrument among older recipients of managed care. J Am Geriatr Soc. 1997;45(5):614-617.

22. Weiner JP, Starfield BH, Steinwachs DM, Mumford LM. Development and application of a population-oriented measure of ambulatory care case-mix. Med Care. 1991;29(5):452-472.

23. Sheehan TJ, DuBrava S, DeChello LM, Fang Z. Rates of weight change for black and white Americans over a twenty year period. Int J Obes Relat Metab Disord. 2003;27(4):498-504.

24. Fried LP, Tangen CM, Walston J, et al. Frailty in older adults: evidence for a phenotype. J Gerontol. 2001;56(3):M146-M156.

\section{Publish your work in this journal}

Risk Management and Healthcare Policy is an international, peerreviewed, open access journal focusing on all aspects of public health, policy, and preventative measures to promote good health and improve morbidity and mortality in the population. The journal welcomes submitted papers covering original research, basic science, clinical \& epidemio- logical studies, reviews and evaluations, guidelines, expert opinion and commentary, case reports and extended reports. The manuscript management system is completely online and includes a very quick and fair peerreview system, which is all easy to use. Visit http://www.dovepress.com/ testimonials.php to read real quotes from published authors. 